\title{
Evaluation of oxidative stress parameters and metabolic activities of nurses working day and night shifts
}

\author{
AVALIAÇÃO DE PARÂMETROS DE ESTRESSE OXIDATIVO E AS ATIVIDADES METABÓLICAS \\ DAS ENFERMEIRAS TRABALHANDO EM TURNOS DIURNOS E NOTURNOS
}

\section{EVALUACIÓN DE PARÁMETROS DE ESTRÉS OXIDATIVO Y ACTIVIDADES METABÓLICAS DE ENFERMERAS TRABAJANDO EN TURNOS DIURNOS Y NOCTURNOS}

\author{
Turgay Ulas ${ }^{1}$, Hakan Buyukhatipoglu², Idris Kirhan ${ }^{3}$, Mehmet Sinan Dal ${ }^{4}$, Sevilay Ulas ${ }^{5}$, Mehmet Emin \\ Demir $^{6}$, Mehmet Ali Eren ${ }^{7}$, Mehmet Ucar ${ }^{8}$, Abdussamet Hazar ${ }^{9}$, İbrahim Can Kurkcuoglu ${ }^{10}$, Nurten Aksoy ${ }^{11}$
}

\section{RESUMO}

O objetivo deste estudo foi avaliar o estresse oxidativo e as atividades metabólicas das enfermeiras em turnos diurnos e noturnos. Enfermeiras da Unidade de Tratamento Intensivo (UTI) ( $n=70)$ e do serviço comum (SC) $(n=70)$ participaram do estudo. Logo no início e ao final dos turnos, amostras de sangue foram obtidas para medir parâmetros de estresse oxidativo. Atividades metabólicas também foram analisadas com o uso da braçadeira SenseWear. Parâmetros de estresse oxidativo aumentaram no fim dos turnos de todas as enfermeiras SC e UTI quando comparados ao início dos turnos. Comparados às enfermeiras SC, os níveis de TAS, TOS e OSI das enfermeiras de UTI não eram significativamente diferentes no final dos turnos diurnos e noturnos. Além disso, as atividades metabólicas das enfermeiras de SC e UTI se revelaram como sendo similares. Assim, os parâmetros de estresse oxidativo e as atividades metabólicas das enfermeiras SC e UTI não eram diferentes, e todas as enfermeiras sofrem efeitos semelhantes dos turnos, tanto no dia quanto na noite.

\section{DESCRITORES}

Enfermeiras

Carga de trabalho

Terapia intensiva

Estresse oxidativo

Biotransformação

\section{ABSTRACT}

The aim of this study was to evaluate the oxidative stress and metabolic activities of nurses working day and night shifts. Intensive care unit (ICU) $(n=70)$ and ordinary service (OS) nurses $(n=70)$ were enrolled in the study. Just before and the end of the shifts, blood samples were obtained to measure the participants' oxidative stress parameters. Metabolic activities were analyzed using the SenseWear Armband. Oxidative stress parameters were increased at the end of the shifts for all OS and ICU nurses compared to the beginning of the shifts. Compared to the OS nurses, the ICU nurses' TAS, TOS, and OSI levels were not significantly different at the end of the day and night shifts. The metabolic activities of the OS and ICU nurses were found to be similar. As a result, the OS and ICU nurses' oxidative stress parameters and metabolic activities were not different, and all of the nurses experienced similar effects from both the day and night shifts.

\section{DESCRIPTORS}

Nurses

Workload

Intensive care

Oxidative stress

Biotransformation

\section{RESUMEN}

Se objetivó evaluar estrés oxidativo y actividades metabólicas de enfermeras en turnos diurnos y nocturnos. Participaron enfermeras de Unidad de Terapia Intensiva (UTI, n=70) y del servicio común (SC, $\mathrm{n}=70$ ). Se obtuvieron muestras sanguíneas al inicio y al final de los turnos para medir parámetros de estrés oxidativo. Las actividades metabólicas también fueron analizadas utilizando brazaletes SenseWear. Los parámetros de estrés oxidativo aumentaron hacia el final de los turnos de todas las enfermeras SC y UTI, comparados con la medida de inicio. Los niveles de TAS, TOS y OSI no eran significativamente diferentes entre enfermeras SC y UTI al cierre de los turnos diurnos y nocturnos. Las actividades metabólicas de enfermeras SC y UTI se mostraron similares. Consecuentemente, los parámetros de estrés oxidativo y las actividades metabólicas de enfermeras SC y UTI no resultaron diferentes, y todas las enfermeras sufren efectos semejantes en sus turnos, tanto diurnos como nocturnos.

\section{DESCRIPTORES \\ Enfermeras \\ Carga de trabajo \\ Cuidados intensivos \\ Estrés oxidativo \\ Biotransformación} ${ }^{1}$ Assistant Prof., Faculty, Department of Internal Medicine, Harran University, Şanlıurfa,Turkey. turgayulas@yahoo.com ${ }^{2}$ Associate Prof., Faculty, Department of
Internal Medicine, Harran University, Şanlıurfa, Turkey. buyukhatipoglu@gmail.com ${ }^{3}$ Specialist Dr., Faculty, Department of Internal Medicine, Harran University,
Şanlıurfa, Turkey. idriskirhan@gmail.com ${ }^{4}$ Specialist Dr., Faculty, Department of Internal Medicine, Dicle University, Diyarbakır, Turkey. dr.sinandal@gmail.
com ${ }^{5}$ Harran University, College of Social Sciences, Department of Public Relations and Publicity, Şanlıurfa, Turkey. sevilaygunduz@gmail.com ${ }^{6}$ Specialist
Dr., Faculty, Department of Internal Medicine, Harran University, Şanlıurfa, Turkey. demirmehmetemin@hotmail.com ${ }^{7}$ Specialist Dr., Faculty, Department
of Internal Medicine, Harran University, Şanlıurfa, Turkey. drmalieren@hotmail.com ${ }^{8}$ Specialist Dr., Department of Physical Therapy and Rehabilitation,
Sanliurfa Training and Research Hospital, Sanliurfa, Turkey. drmehmetucar@msn.com ${ }^{9}$ Asistant Prof., Faculty, Department of Thoracic and Cardiovascular
Surgery, Harran University, Sanliurfa, Turkey. drasamet@hotmail.com ${ }^{10}$ Associate Prof., Ibrahim Can Kurkcuoglu, Faculty, Department of Chest Surgery,
Harran University, Şanlıurfa, Turkey. cankurkcuoglu@gmail.com ${ }^{11}$ Prof. Dr., Faculty, Department of Biochemistry, Harran University, Sanlıurfa, Turkey.
nurtenaksoy@yahoo.com 


\section{INTRODUCTION}

The number of shift workers has rapidly increased worldwide over the last few decades. Nurses work long hours under highly stressful conditions, and they often suffer from excessive workloads and minimal social support. Nurses working long-term night and shift work become more cynical and less empathetic as their training progresses and might develop many health-related problems, such as fatigue, sleep problems, anxiety and difficulties in maintaining regular lifestyles. Reduced rest and recovery times lead to physiologic depletion or exhaustion that continues into the next workday. Consequently, shift workers have an increased prevalence of being unhealthy. However, whether prolonged physical and extreme workload and mental stress induce relevant metabolic changes remains poorly understood ${ }^{(1-5)}$. Oxidative stress is believed to have a role in the development of chronic diseases. After the balance between reactive oxygen species production and antioxidative defense activity is disrupted, oxidative stress can occur, which may result in cell injury or death, subsequent tissue damage, and, finally, chronic disease ${ }^{(6-7)}$. Additionally, increased oxidative stress associated with different jobs has been demonstrated by isolated studies. However, exhaustive and prolonged working also has been shown to increase oxidative stress in shift workers ${ }^{(8-11)}$.

Despite the factors mentioned above, until now, no clinical research has been performed to evaluate the oxidative stress parameters by comparing the metabolic activities of the nurses. In this study, we evaluated and compared metabolic activities using the SWA and oxidative stress parameters of the nurses working in the ordinary services (OS) and intensive care units (ICU) on day and night shifts. The present study was undertaken to demonstrate whether oxidative stress and metabolic activities of the nurses increased in prolonged and shift work.

\section{METHOD}

\section{Study design and nurses}

This prospective study was conducted at the Harran University School of Medicine, Sanliurfa, Turkey. Prior to subject recruitment, the study protocol was reviewed and approved by the local ethics committee (ethical approval number; 28.01.2010: B.10.IEGO.0.11.00.01/021) in accordance with the ethical principles for human investigations, as outlined by the Second Declaration of Helsinki. Written informed consent was obtained from all the nurses. From October 2010 to September 2011, 140 nurses working in the ICUs (medical, surgical, coronary, general, neonatal) and OSs (internal medicine, neurology, orthopedics, general surgery, pediatrics, obstetrics and gynecology, cardiology, Thoracic and Cardiovascular Surgery, Pediatric
Surgery) at Harran University Hospital were consecutively enrolled in the study.

The study subjects were divided into 2 groups: 1 ) the day shift group $(n=70)$ consisted of nurses working from 8 a.m. to 4 p.m. ( 8 hours), and 2) the night shift group ( $n=70)$ consisted of nurses working from 4 p.m. to 8 a.m. (16 hours). Both groups were further divided: day shift ICU group and night shift ICU group (both $n=35$ ) and day shift OS group and night shift OS group (both $n=35$ ). The exclusion criteria were as follows: recent acute infectious illness, such as respiratory or gastrointestinal infections, any inflammatory or infiltrative disorders, any evidence of liver, kidney, or respiratory disease, diabetes mellitus, malignancy, the use of any systemic drug that could affect the SWA, thermoregulatory process, bodyweight or metabolism, regular alcohol use, smoking, pregnancy, depression and psychiatric or neurological disorders. Just before the shift began, blood samples were obtained to measure the total antioxidant status (TAS) and total oxidant status (TOS). After the shift, blood samples were obtained again to measure the TAS and TOS. Total EE, metabolic equivalents of a task (METs), number of steps, active EE and physical activity duration were analyzed from all subjects at the end of the shift using SWA.

\section{Baseline definitions and measurements}

Weight and height were measured according to standardized protocols. Body mass index was calculated as the weight in kilograms divided by the height in meters squared $\left(\mathrm{kg} / \mathrm{m}^{2}\right)$. Blood pressure was measured by using a sphygmomanometer.

\section{Biochemical analysis}

All blood samples were drawn from a large antecubital vein without interrupting venous flow and using a 19-gauge butterfly needle connected to a plastic syringe. Twenty milliliters of blood was drawn, with the first few milliliters discarded. The residual content of the syringe was transferred immediately to polypropylene tubes, which were then centrifuged at $3000 \mathrm{rpm}$ for 10 minutes at 10 to $18^{\circ} \mathrm{C}$. Supernatant plasma samples were stored in plastic tubes at $-80^{\circ} \mathrm{C}$ until assayed. For the serum markers of oxidant stress, TOS was measured and the oxidative stress index (OSI) calculated. TAS was measured as an indicator of antioxidant status.

\section{Measurement of total oxidant status}

Serum TOS was measured using a novel automated method developed by Erel ${ }^{(12)}$. Oxidants present in the sample oxidize the ferrous ion-o-dianisidine complex to ferric ion. The oxidation reaction is enhanced by glycerol molecules, which are abundant in the reaction medium. The ferric ion generates a colored complex with Xylenol orange in an acidic medium. Color intensity, which can be measured
Evaluation of oxidative stress parameters and metabolic activities of nurses working day and night shifts Ulas T, Buyukhatipoglu H, Kirhan I, Dal MS, Ulas S, Demir ME, Eren MA, Ucar M, Hazar A, Kurkcuoglu IC, Aksoy N 
spectrophotometrically (V-530; Jasco ${ }^{\circ}$, Tokyo, Japan), is related to the quantity of oxidant molecules present in the sample. The assay is calibrated with hydrogen peroxide, and the results are expressed in terms of micro-molar hydrogen peroxide equivalents per liter ( $\mu \mathrm{mol} \mathrm{H} 2 \mathrm{O} 2$ equiv./I).

\section{Measurement of total antioxidant status}

Serum TAS was measured using a novel automated method developed by Erel (12). In this method, hydroxyl radical, the most potent biological radical, is produced. In the assay, ferrous ion solution in reagent 1 is mixed with hydrogen peroxide present in reagent 2 . Sequentially produced radicals, such as the brown-colored dianisidine radical cation produced by the hydroxyl radical, are also potent radicals. This method allows measurement of the antioxidative effect of the sample against the potent freeradical reactions that are initiated by the hydroxyl radical. The assay has excellent precision values of more than $97 \%$. The results are expressed as mmol Trolox equiv./I.

\section{Oxidative stress index}

The OSI was defined as the ratio of the TOS to TAS levels. For the calculation, TAS units were changed to $\mathrm{mmol} / \mathrm{I}$ and the OSI value calculated according to the following formula(12): OSI (arbitrary unit) = TOS ( $\mu \mathrm{mol} \mathrm{H} 2 \mathrm{O} 2$ equiv./I)//TAS (mmol Trolox equiv./I).

\section{Analyzing metabolic activity parameters by SWA}

The SenseWear Pro Armband ${ }^{\mathrm{TM}}$ Version 6.1 (BodyMedia, Inc., Pittsburgh, PA, USA) is a portable device measuring $8.8 \times 5.6 \times 2.1 \mathrm{~cm}$ in size and $82 \mathrm{~g}$ in weight; the armband, which was the most recent version, was provided by the manufacturer for this study. The SWA utilizes a multi-sensor array including a 2-axis accelerometer, heat flux sensor, galvanic skin response sensor, skin temperature sensor, and a nearbody ambient temperature sensor and has been validated in clinical patients. The SWA was placed on the dominant arm over the triceps at the midpoint between the acromion and olecranon processes. The subject's age, gender, weight and height were programmed into the SWA. The total EE, METs, number of step counts, active EE and physical activity duration were analyzed with InnerView Research Software (version 6.1), which was provided by BodyMedia, Inc. METs define the EE related to body weight. One MET is equivalent to a metabolic rate consuming 1 kilo calorie per kilogram of body weight per hour (1 kcal/kg body weight/hour). Active $\mathrm{EE}$ and physical activity duration were defined as requiring at least two consecutive minutes at 3.0 METs or higher ${ }^{(13-14)}$.

\section{Statistical analysis}

All of the statistical analyses were performed using SPSS for Windows version 17.0 (SPSS, Chicago, IL, USA). After the shift and baseline differences of TAS and TOS levels were calculated, Kolmogorov-Smirnov tests were used to test the normality of data distribution. The data were expressed as arithmetic means and standard deviations. Independent sample T-test and Mann-Whitney $U$-tests were used in nor- mally and non-normally distributed continuous variables between groups, respectively. Paired t-tests and Wilcoxon signed-rank tests were used to analyze the changes within each group. Pearson's correlation analysis was used to examine the association of oxidative stress parameters and metabolic activities in all groups. A two-sided $p$ value $<0.05$ was considered statistically significant.

\section{RESULTS}

Day shift group results: The clinical, biochemical and demographic characteristics of the study subjects are shown in Table 1. There were no statistical differences in the biochemical and demographic characteristics among the subgroups ( $p>0.05$ for all). Compared to the day shift OS group, the day shift ICU group was not significantly different regarding the TAS, TOS, and OSI levels at baseline and the end of the shift ( $p>0.05$ for all). Similarly, the total EE, METs, number of steps, active EE, physical activity durations, difference of TAS and TOS levels were not significantly different in the day shift OS and day shift ICU groups ( $p>0.05$ for all). In addition, compared to baseline, the TAS levels were significantly decreased at the end of the shift, and the TOS and OSI levels were both significantly increased in the two groups ( $p<0.05$ for all) (Table 1,2 ).

Table 1 - Comparison of demographic, laboratory and clinical characteristics of the day shift nurses - Sanliurfa, 2011

\begin{tabular}{|c|c|c|c|}
\hline & $\begin{array}{l}\text { Day shift ICU } \\
\text { Group }(n=35)\end{array}$ & $\begin{array}{l}\text { Day Shift OS } \\
\text { Group }(n=35)\end{array}$ & $\mathbf{p}$ \\
\hline Gender, female & 35 & 35 & \\
\hline Age, years & $27.54 \pm 4.42$ & $29.12 \pm 3.71$ & $0.111^{\mathrm{a}}$ \\
\hline BMI, $\mathrm{kg} / \mathrm{m}^{2}$ & $24.12 \pm 4.53$ & $23.36 \pm 4.81$ & $0.325^{\mathrm{a}}$ \\
\hline Systolic BP, mmHg & $112.16 \pm 8.47$ & $108.34 \pm 7.57$ & $0.095^{\mathrm{a}}$ \\
\hline Diastolic BP, mmHg & $69.22 \pm 7.08$ & $72.69 \pm 8.34$ & $0.310^{\mathrm{a}}$ \\
\hline Total EE, calorie & $954.37 \pm 145.00$ & $897.94 \pm 221.45$ & $0.212^{\mathrm{a}}$ \\
\hline Average METs & $2.13 \pm 0.23$ & $1.99 \pm 0.35$ & $0.074^{\mathrm{a}}$ \\
\hline Steps & $6249.54 \pm 1654.57$ & $5483.60 \pm 2099.57$ & $0.095^{\mathrm{a}}$ \\
\hline Active EE, calorie & $203.40 \pm 143.91$ & $165.22 \pm 150.02$ & $0.281^{\mathrm{a}}$ \\
\hline $\begin{array}{l}\text { Physical activity } \\
\text { duration, minute }\end{array}$ & $64.94 \pm 48.03$ & $57.48 \pm 55.02$ & $0.120^{\mathrm{b}}$ \\
\hline $\begin{array}{l}\text { TAS at } 8 \text { a.m., } \mu \mathrm{mol} \\
\mathrm{H} 2 \mathrm{O} 2 \text { equiv./1 }\end{array}$ & $1.01 \pm 0.10$ & $0.99 \pm 0.12$ & $0.534^{\mathrm{a}}$ \\
\hline $\begin{array}{l}\text { TOS at } 8 \text { a.m., mmol } \\
\text { Trolox equiv./1 }\end{array}$ & $10.13 \pm 2.06$ & $9.54 \pm 1.67$ & $0.201^{\mathrm{a}}$ \\
\hline $\begin{array}{l}\text { OSI at } 8 \text { a.m., } \\
\text { arbitrary unit }\end{array}$ & $1.00 \pm 0.21$ & $0.97 \pm 0.21$ & $0.511^{\mathrm{a}}$ \\
\hline $\begin{array}{l}\text { TAS at } 4 \text { p.m., } \mu \mathrm{mol} \\
\mathrm{H} 2 \mathrm{O} 2 \text { equiv./1 }\end{array}$ & $0.93 \pm 0.13$ & $0.95 \pm 0.14$ & $0.513^{\mathrm{a}}$ \\
\hline $\begin{array}{l}\text { TOS at } 4 \text { p.m., mmol } \\
\text { Trolox equiv./1 }\end{array}$ & $11.21 \pm 3.38$ & $11.39 \pm 3.78$ & $0.842^{\mathrm{a}}$ \\
\hline $\begin{array}{l}\text { OSI at } 4 \text { p.m., } \\
\text { arbitrary unit }\end{array}$ & $1.24 \pm 0.47$ & $1.21 \pm 0.39$ & $0.778^{\mathrm{a}}$ \\
\hline Difference of TAS & $-0.08 \pm 0.17$ & $-0.04 \pm 0.13$ & $0.311^{\mathrm{a}}$ \\
\hline Difference of TOS & $1.08 \pm 3.00$ & $1.84 \pm 3.87$ & $0.367^{\mathrm{a}}$ \\
\hline
\end{tabular}

All of the measurable values are provided with mean \pm standard deviation ICU: intensive care unit, OS: ordinary service, NS: non-significant, BP blood pressure, BMI: body mass index, EE: energy expenditure, TOS: tota oxidant status, TAS: total antioxidant status, OSI: oxidative stress index. By independent sample T-testa and Mann-Whitney Ub-tests 
Table 2 - Comparison of baseline and at the end of the day shift oxidative stress parameters -Sanliurfa, 2011

\begin{tabular}{lcccccc}
\hline & \multicolumn{3}{c}{ Day shift ICU Group (n=35) } & \multicolumn{3}{c}{ Day Shift OS Group (n=35) } \\
\cline { 2 - 7 } & At 8 a.m & At 4 p.m. & p & At 8 a.m. & At 4 p.m. & p \\
\hline TAS, $\mu$ mol H2O2 equiv./1 & $1.01 \pm 0.10$ & $0.93 \pm 0.13$ & $0.006^{\mathrm{a}}$ & $0.99 \pm 0.12$ & $0.95 \pm 0.14$ & $0.047^{\mathrm{a}}$ \\
TOS, mmol Trolox equiv./1 & $10.13 \pm 2.06$ & $11.21 \pm 3.38$ & $0.040^{\mathrm{a}}$ & $9.54 \pm 1.67$ & $11.39 \pm 3.78$ & $0.008^{\mathrm{a}}$ \\
OSI, arbitrary unit & $1.00 \pm 0.21$ & $1.24 \pm 0.47$ & $0.003^{\mathrm{a}}$ & $0.97 \pm 0.21$ & $1.21 \pm 0.39$ & $0.001^{\mathrm{a}}$ \\
\hline
\end{tabular}

All of the measurable values are provided with mean \pm standard deviation. ICU: intensive care unit, OS: ordinary service, TOS: total oxidant status, TAS: total antioxidant status, OSI: oxidative stress index. By paired sample Ta test

Night shift group results: The clinical, biochemical and demographic characteristics of the study subjects are shown in Table 3. There were no statistical differences in the biochemical and demographic characteristics among the subgroups ( $p>0.05$ for all). Compared to the night shift OS group, the night shift ICU group was not significantly different regarding the TAS, TOS, and OSI levels at baseline and the end of the shift ( $p>0.05$ for all). Similarly, the total EE, METs, number of steps, active $E E$, physical activity durations, difference of TAS and TOS levels were not significantly different in the night shift OS and night shift ICU groups ( $p>0.05$ for all). In addition, at the end of the shift, the TAS levels were significantly decreased compared to baseline, and the TOS and OSI levels were both significantly increased in the two groups ( $p<0.05$ for all) (Table 3, 4).

Table 3 - Comparison of demographic, laboratory and clinical characteristics of the night shift nurses - Sanliurfa, 2011

\begin{tabular}{lccc}
\hline & Night shift ICU Group (n=35) & Night Shift OS Group (n=35) & p \\
\hline Gender, female & 35 & 35 & $26.88 \pm 3.92$ \\
Age, years & $28.14 \pm 4.46$ & $22.87 \pm 3.43$ & $0.168^{\mathrm{a}}$ \\
BMI, $\mathrm{kg} / \mathrm{m}^{2}$ & $23.54 \pm 3.41$ & $119.41 \pm 9.33$ & $0.357^{\mathrm{a}}$ \\
Systolic BP, mmHg & $116.14 \pm 12.51$ & $73.55 \pm 7.08$ & $0.173^{\mathrm{a}}$ \\
Diastolic BP, mmHg & $71.26 \pm 8.12$ & $1683.11 \pm 301.71$ & $0.326^{\mathrm{a}}$ \\
Total EE, calorie & $1719.85 \pm 242.56$ & $1.83 \pm 0.28$ & $0.576^{\mathrm{a}}$ \\
Average METs & $1.96 \pm 0.33$ & $9398.94 \pm 3561.46$ & $0.067^{\mathrm{a}}$ \\
Steps & $10302.40 \pm 2646.67$ & $247.85 \pm 185.49$ & $0.233^{\mathrm{a}}$ \\
Active EE, calorie & $318.14 \pm 285.17$ & $75.82 \pm 59.99$ & $0.196^{\mathrm{a}}$ \\
Physical activity duration, minute & $93.00 \pm 71.48$ & $1.06 \pm 0.21$ & $0.452^{\mathrm{b}}$ \\
TAS at 4 p.m., $\mu$ mol H2O2 equiv./1 & $1.03 \pm 0.12$ & $10.85 \pm 2.67$ & $0.486^{\mathrm{a}}$ \\
TOS at 4 p.m., mmol Trolox equiv./1 & $11.18 \pm 3.31$ & $1.05 \pm 0.34$ & $0.648^{\mathrm{a}}$ \\
OSI at 4 p.m., arbitrary unit & $1.09 \pm 0.34$ & $0.91 \pm 0.09$ & $0.658^{\mathrm{a}}$ \\
TAS at 8 a.m., $\mu$ mol H2O2 equiv./1 & $0.91 \pm 0.14$ & $13.35 \pm 5.12$ & $0.793^{\mathrm{a}}$ \\
TOS at 8 a.m., mmol Trolox equiv./1 & $12.92 \pm 3.35$ & $1.47 \pm 0.53$ & $0.681^{\mathrm{a}}$ \\
OSI at 8 a.m., arbitrary unit & $1.39 \pm 0.51$ & $0.15 \pm 0.23$ & $0.522^{\mathrm{a}}$ \\
Difference of TAS & $0.11 \pm 0.17$ & $-2.49 \pm 5.85$ & $0.464^{\mathrm{a}}$ \\
Difference of TOS & $-1.09 \pm 3.96$ & $0.246^{\mathrm{a}}$ \\
\hline
\end{tabular}

All of the measurable values are provided with mean \pm standard deviation. ICU: intensive care unit, OS: ordinary service, NS: non-significant, BP: blood pressure, BMI: body mass index, TOS: total oxidant status, TAS: total antioxidant status, OSI: oxidative stress index. By Independent sample T-testa and Mann-Whitney Ub-tests

Table 4 - Comparison of oxidative stress parameters at baseline and the end of the night shift- Sanliurfa, 2011

\begin{tabular}{lcccccc}
\hline & \multicolumn{3}{c}{ Night shift ICU Group (n=35) } & \multicolumn{3}{c}{ Night Shift OS Group (n=35) } \\
\cline { 2 - 7 } & At 8 a.m & At 4 p.m. & p & At 8 a.m. & At 4 p.m. & p \\
\hline TAS, $\mu$ mol H2O2 equiv./1 & $1.03 \pm 0.12$ & $0.91 \pm 0.14$ & $0.001^{\mathrm{a}}$ & $1.06 \pm 0.21$ & $0.91 \pm 0.09$ & $0.001^{\mathrm{a}}$ \\
TOS, mmol Trolox equiv./1 & $11.18 \pm 3.31$ & $12.92 \pm 3.35$ & $0.004^{\mathrm{a}}$ & $10.85 \pm 2.67$ & $13.35 \pm 5.12$ & $0.016^{\mathrm{a}}$ \\
OSI, arbitrary unit & $1.09 \pm 0.34$ & $1.39 \pm 0.51$ & $0.006^{\mathrm{a}}$ & $1.05 \pm 0.34$ & $1.47 \pm 0.53$ & $0.001^{\mathrm{a}}$ \\
\hline
\end{tabular}

All of the measurable values are provided with mean \pm standard deviation. ICU: intensive care unit, OS: ordinary service, TOS: total oxidant status, TAS: total antioxidant status, OSI: oxidative stress index. A paired sample Ta-test was used

In the bivariate analysis, no correlations were found between oxidative stress parameters and metabolic activities in all the groups ( $p>0.05$ for all).

\section{DISCUSSION}

The main findings of this study were as follows: (i) the oxidative stress parameters were increased at the end of the shifts in all OS and ICU nurses compared to the begin- ning of the shifts; (ii) compared to the OS nurses, the ICU nurses' TAS, TOS, and OSI levels were not significantly different at the end of the day and night shifts; and (iii) the metabolic activities of the OS and ICU nurses were found to be similar.

It is known that stressful working conditions and/or poor work-related health outcomes exist among healthcare workers, generally nursing personnel, and there are multiple and important stressors at the clinics and hospitals
Evaluation of oxidative stress parameters and metabolic activities of nurses working day and night shifts Ulas T, Buyukhatipoglu H, Kirhan I, Dal MS, Ulas S, Demir ME, Eren MA, Ucar M, Hazar A, Kurkcuoglu IC, Aksoy N 
where nursing personnel generally work ${ }^{(15-18)}$. Some studies have concluded that inadequate work planning and a poorly organized work schedule may impact health. In particular, this impact may result in a reduced quantity and quality of sleep, a decline in cognitive and physical performance and an associated increased risk for errors, and interference with family and social engagements. Additionally, previous research studies on night shift working have also observed the risks or factors associated with the pathophysiology, lifestyle behavior and job-related conditions and impaired circadian rhythm ${ }^{(19-21)}$. In the literature, limited numbers of research studies have been performed to evaluate the oxidative stress parameters of the shift nurses; however, no research study has been performed to investigate the metabolic activities of the nurses on their shifts. Studies that have been previously performed have shown an increased oxidative stress in nurses working on their shifts ${ }^{(4,}$ ${ }^{9-11)}$. Beyond the previous published studies, we found an increased oxidative stress at the end of shifts in all nurses compared to baseline parameters. Furthermore, we compared OS and ICU nurses' oxidative stress parameters and metabolic activities using the SWA device on their shifts and found no differences among them. In other words, the findings of the present study demonstrated that although oxidative stress was increased, we observed no difference in the metabolic activities in the nurses, and most likely, the job stress and prolonged and incessant working hours were the main reasons for the increased oxidative stress. This study is unique regarding this point.

Measuring different oxidant and antioxidant molecules is impractical, and their oxidant and antioxidant effects are additive. Because there are numerous oxidants and antioxidants in the body, measuring total oxidant-antioxidant status is more valid and reliable ${ }^{(12)}$. If only a few parameters are measured, their levels may be unchanged or decreased, even when the actual oxidant status is increased, or vice versa ${ }^{(22)}$. There is considerable interest in the habitual physical activity levels and total EE of contemporary humans given the burden of inactivity-related disorders. Therefore, a requirement for accurate, nonintrusive, reliable and valid methods for the measurement of physical activity and predicting EE is warranted to tackle important health issues ${ }^{(13-14)}$. The doubly labeled water method, indirect calorimetry and metabolic carts are considered to be the gold standard techniques for EE assessment. However, these techniques cannot easily assess free-living subjects in everyday life because of their methodological complexity, limited practicality, and/or high cost. SWA is a valid, reliable, portable, practical and easily accessible device that reports physical activities and predicts $\mathrm{EE}^{(13-14)}$. For these reasons, we used TOS and TAS levels in our study along with the SWA device to determine the metabolic activities of the nurses in our study.

The resting times, workloads, occupational roles, activities of the nurses between the different ICUs and Oss, and the number and illness severities of the patients in these units may not have been comparable among the shifts. However, our study confirmed that all of the day and night shift nurses both in the ICUs and OSs had similar metabolic activities, which were standardized by the SWA device. Although we did not find any correlation between the oxidative stress parameters and the metabolic activities of the nurses, presumably other factors, such as job stress and long shifts, may have played a role in the increased oxidative stress levels. Moreover, although all of the nurses were healthy, we hypothesized that increased workload without sufficient time to rest, along with highlevel job stress, might disrupt oxidative and antioxidative balance, thereby causing oxidative stress in on-duty nurses. However, the mechanisms of these effects are poorly understood and contentious.

\section{CONCLUSION}

The results of this study raise concerns regarding the long-term influences of oxidative stress on the health of nurses because oxidative stress has been implicated in the pathophysiology of a large number of diseases. Note that the sample size of this study was relatively small, and it involved a single center. Moreover, analyzing stressing conditions with oxidative stress parameters and metabolic activities of the nurses working in the ICUs and OSs might add to the value of our manuscript. Therefore, these results should be verified with large-scale, multicenter prospective studies that are conducted using modern technologies and methods. Clearly, further research into this area is warranted.

\section{REFERENCES}

1. Corradi-Webster CM, Carvalho AM. Dialogues in psychology and nursing in a time of shifting paradigms. Rev Esc Enferm USP [Internet]. 2011 [cited 2012 Mar 16];45(4):974-80. Available from: http://www.scielo.br/pdf/reeusp/v45n4/en_v45n4a26.pdf

2. Pafaro RC, De Martino MM. Study on stress among nurses working in two shifts at a pediatric oncology hospital in Campinas. Rev Esc Enferm USP. 2004;38(2):152-60.

3. De Martino MM, Misko MD. Emotional states of nurses in professional performance at Intensive Care Units. Rev Esc Enferm USP. 2004;38(2):161-7.

4. Buyukhatipoglu H, Kirhan I, Vural M, Taskin A, Sezen Y, Dag OF, et al. Oxidative stress increased in healthcare workers working 24-hour on-call shifts. Am J Med Sci. 2010;340(6):462-7. 
5. Nasrabadi AN, Seif H, Latifi M, Rasoolzadeh N, Emami A. Night shift work experiences among Iranian nurses: a qualitative study. Int Nurs Rev. 2009;56(4):498-503.

6. Fitzmaurice SD, Sivamani RK, Isseroff RR. Antioxidant therapies for wound healing: a clinical guide to currently commercially available products. Skin Pharmacol Physiol. 2011;24(3):113-26.

7. Halliwell B, Gutteridge JM, Cross CE. Free radicals, antioxidants, and human disease: where are we now? J Lab Clin Med. 1992;119(6):598-620.

8. Tsuboi H, Tatsumi A, Yamamoto K, Kobayashi F, Shimoi K, Kinae N. Possible connections among job stress, depressive symptoms, lipid modulation and antioxidants. J Affect Disord. 2006;91(1):63-70.

9. Flore R, Gerardino L, Santoliquido A, Catananti C, Pola P, Tondi $P$. Reduction of oxidative stress by compression stockings in standing workers. Occup Med (Lond). 2007;57(5):337-41.

10. Ishihara I, Nakano M, Ikushima M, Hara Y, Yoshimine T, Haraga $M$, et al. Effect of work conditions and work environments on the formation of 8-OH-dG in nurses and non-nurse female workers. J UOEH. 2008;30(3):293-308.

11. Sharifian A, Farahani S, Pasalar P, Gharavi M, Aminian O. Shift work as an oxidative stressor. J Circadian Rhythms. 2005;3:15.

12. Buyukhatipoglu H, Sezen Y, Yildiz A, Bas M, Kirhan I, Ulas T, et al. $\mathrm{N}$-acetylcysteine fails to prevent renal dysfunction and oxidative stress after noniodine contrast media administration during percutaneous coronary interventions. Pol Arch Med Wewn. 2010;120(10):383-9.

13. Berntsen S, Hageberg R, Aandstad A, Mowinckel P, Anderssen $\mathrm{SA}$, Carlsen $\mathrm{KH}$, et al. Validity of physical activity monitors in adults participating in free-living activities. Br J Sports Med. 2010;44(9):657-64.
14. Almeida GJ, Wasko MC, Jeong K, Moore CG, Piva SR. Physical activity measured by the SenseWear Armband in women with rheumatoid arthritis. Phys Ther. 2011;91(9): 1367-76.

15. Borges FN, Fischer FM. Twelve-hour night shifts of healthcare workers: a risk to the patients? Chronobiol Int. 2003;20(2):351-60.

16. Trinkoff A, Geiger-Brown J, Brady B, Lipscomb J, Muntaner C. How long and how much are nurses now working? Am J Nurs. 2006;106(4):60-71.

17. Clissold G, Smith P, Acutt B. The impact of unwaged domestic work on the duration and timing of sleep of female nurses working full-time on rotating 3-shift rosters. J Hum Ergol (Tokyo). 2001;30(1-2):345-9.

18. Portela LF, Rotenberg L, Waissmann W. Self-reported health and sleep complaints among nursing personnel working under $12 \mathrm{~h}$ night and day shifts. Chronobiol Int. 2004;21(6):859-70.

19. Dorrian J, Lamond N, van den Heuvel C, Pincombe J, Rogers $A E$, Dawson D. A pilot study of the safety implications of Australian nurses' sleep and work hours. Chronobiol Int. 2006;23(6):1149-63.

20. Fischer FM, Borges FN, Rotenberg L, Latorre Mdo R, Soares NS, Rosa PL, et al. Work ability of health care shift workers: what matters? Chronobiol Int. 2006;23(6): 1165-79.

21. Camerino D, Conway PM, Sartori S, Campanini P, EstrynBéhar $\mathrm{M}$, van der Heijden $\mathrm{BI}$, et al. Factors affecting work ability in day and shift-working nurses. Chronobiol Int. 2008;25(2):425-42.

22. Erel O. A new automated colorimetric method for measuring total oxidant status. Clin Biochem. 2005;38(12):1103-11. 